\title{
Immigration and its Effects on Demographic Change in Spain
}

\author{
Richard R. Verdugo ${ }^{1, *}$ and David Swanson ${ }^{2}$ \\ ${ }^{I}$ National Education Association, Washington, DC. USA \\ ${ }^{2}$ Department of Sociology, University of California at Riverside, Riverside, California, USA
}

\begin{abstract}
The question we attempt to answer in our paper is, "Does immigration have an impact on demographic change in Spain?" We chose Spain for our analysis for a number of reasons, but the two most important are, the significant increase in the immigration population in Spain, especially in the past decade, and the complexities involved in finding an answer to our research question would be overwhelming if two or more nations were to be examined. So a case study seemed a reasonable alternative.

Our analysis involves examining fertility, mortality, and population growth between immigrants, non-immigrants, and the total Spanish population over time. In a second analysis we use a simple difference equation in evaluating the direct impact of immigration on population change in Spain. Our findings suggest, for the period covered in our study, that immigrants have had and are having a significant impact on demographic change in Spain.
\end{abstract}

Keywords: Mortality, fertility, immigration, demographic change, Spain.

\section{INTRODUCTION}

The challenge of demographics can be daunting. Many Western European countries are being challenged by issues related to immigration and how they affect demographic change $[1,2]$. Along with fertility and mortality, immigration forms an important tripartite defining the concept demographic change.

Faced with low fertility rates, declining mortality rates, and a serious need for labor in order to support an ageing and declining population, some European countries, especially those in Western Europe, have turned to immigrants as a way of meeting their labor needs. In the 1950s, some European countries sought agreements with such countries as Italy, Greece, Turkey, and a few Eastern European nations as a strategy to fill important unskilled or semi-skilled jobs [35]. These agreements were made under the assumption that immigrants would return to their home countries after their work was completed, but in many cases that did not happen.

While immigration has become an important topic in policy debates throughout Western Europe, immigrants continue to move into Europe and their presence appears to be affecting the demography of their host countries. But how, exactly, are immigrants affecting the demography of their host countries, and if so, are the effects positive or negative?

Evaluating the impact immigration has on demographic change in two or more nations can be a complex task. An alternative, a case study that focuses on one nation seems like an excellent strategy. By focusing on one nation we can comprehensively analyze the impact immigration has on

*Address correspondence to this author at the National Education Association, Washington, DC, USA; Tel: 202-822-7453; Fax: 202-822-7578; E-mail: Rverdugo@nea.org. demographic change. Moreover, results from such a research endeavor may be used as a benchmark in comparing other European nations. In our study, we focus on Spain.

Why Spain? There are three reasons why we chose Spain for our analysis. First, Spain has a large immigrant population that comprised nearly 9 percent of its population in 2008. Spain has only recently experienced significant growth in its immigrant population, since about 1995/96, in fact. Prior to those years, especially in the 1950s and 1960s, Spain was primarily a sending rather than a receiving country $[2,5-$ 8]. So it is an opportune time for examining the impact immigration is having on demographic change in Spain. Second, the immigrant population in Spain is very diverse, with immigrants coming from South America, Morocco, and Eastern Europe [3]. (Though, we should point out we do not engage in looking at this diversity.) Finally, most studies about immigrants and their impact on European countries seem to focus on Northern European nations, such as France, Germany and the Netherlands $[3,6,7]$. What is interesting about the North-South European Divide, in terms of demographic change, is that while many Northern European nations were experiencing low fertility rates and declining populations, the Southern European nations were experiencing population growth. Since the end of the $20^{\text {th }}$ Century, the pattern has reversed and it is now the Southern European countries that are having low fertility rates and declining populations [6]. Our paper hopes to fill an important void by focusing on Spain, a country with a relatively recent history of being pro-immigrant and where the immigrant population appears to have a significant effect on its demographic profile.

The purpose of our paper is to examine the effect immigration has had on demographic change in Spain. We employ publicly available data from the Instituto Nacional de Estadistica in conducting our research, and begin by describ- 


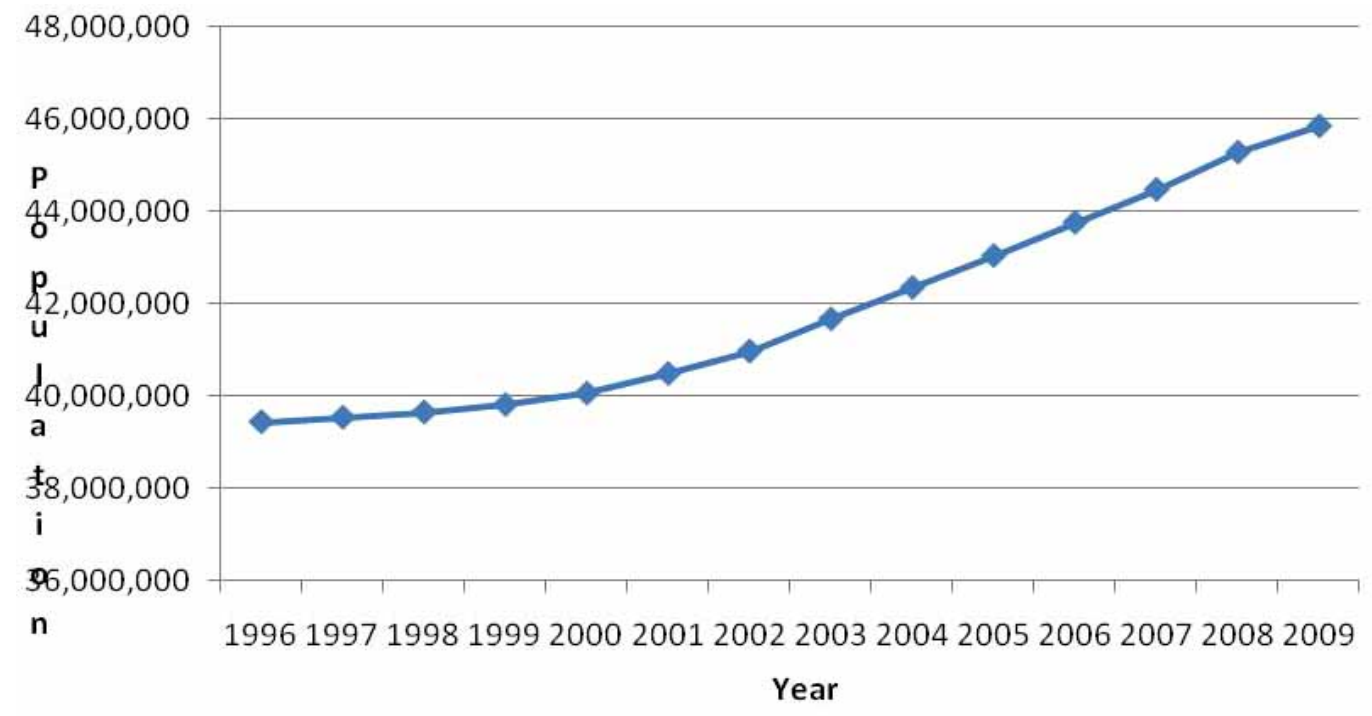

Source: www.epp.eurostat..ec.europa.eu

Fig. (1). Population in Spain: 1996-2009.

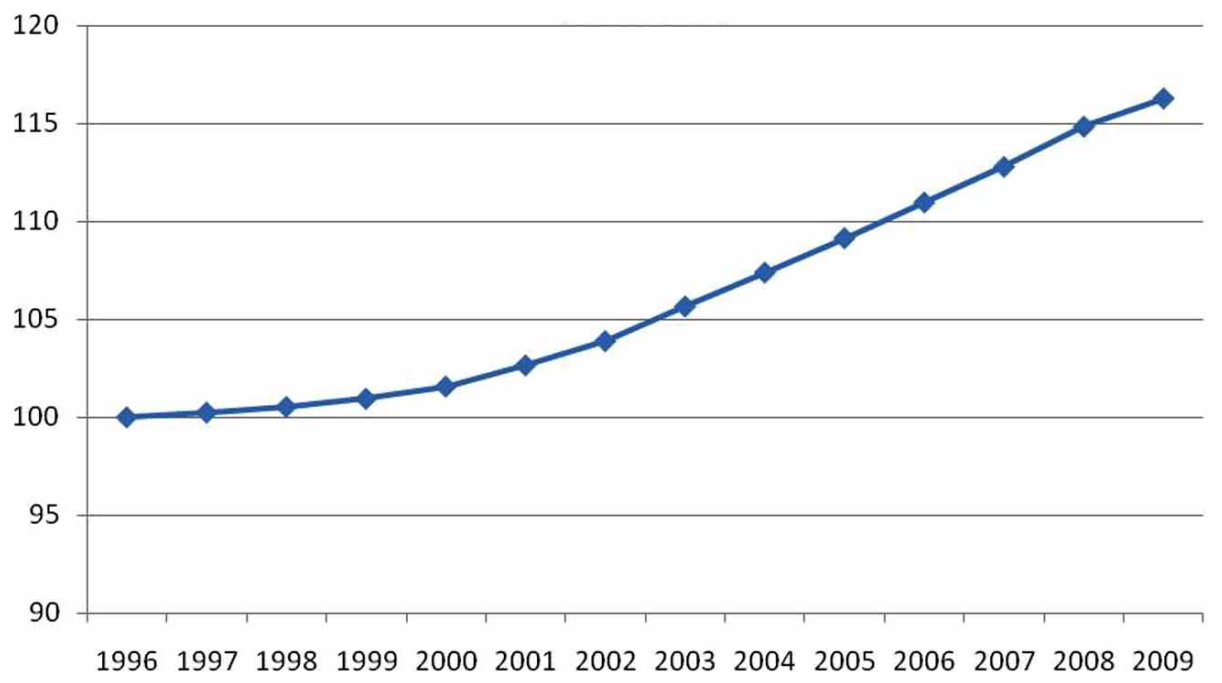

Source: www.epp.eurostat..ec.europa.eu

Fig. (2). National Population Relative Change, Spain: 1996-2009 (1996=100).

ing the overall demographic profile of both the Spanish population and its immigrant population. A second analysis uses a simple difference equation and evaluates the impact immigration has on demographic change.

\section{ANALYSIS}

\section{A. Demographic Change in Spain: An Overview}

\section{Population growth in Spain: 1998 to 2008}

Between 1998 and 2008, the Spanish population grew by slightly over 16 percent (16.29\%). In 1998, the Spanish population stood at $39,852,651$, and by 2008 it had grown to $46,157,822$. There seems to have been a "take-off" point around 2000, and thereafter Spain has realized steady population growth. Fig. (1) charts this growth.
There are three other population measures that can be used to examine the growth in the Spanish population: natural population change (NPC), population change (PC), and relative population change (RPC).

NPC is the difference between the number of live births and the number of deaths per 1000 population. In 1997, the NPC population in Spain was $0.49 / 1000$ and by 2008 it rose to $2.38 / 1000$. Population change (PC) is the difference between the size of the population at the end and the beginning of a period $\left(\mathrm{P}_{\mathrm{e}}-\mathrm{P}_{\mathrm{b}}\right)$. In the interval 1998-09, the PC in Spain was 349,509 and it grew to 957,085 by $2007-08$. Finally, we looked at the RPC, as exhibited in Fig. (2) (base year is 1996). Note the steep rise in the population from 1996 to 2009. The year 2000 is an important point of departure as the Spanish population began to grow dramatically. This growth 
is in line with what previous research has suggested [see 6]. We can conclude that the Spanish population significantly grew between 1996 and 2009.

\section{Components of Demographic Change in Spain: An Overview}

The three components of demographic change are fertility, mortality, and migration. Not only do these three factors affect demographic change, but immigration may have important effects on fertility and mortality as well. In fact, there is considerable debate about the role immigration has in both fertility and mortality rates [2, 4, 8-14]. The general consensus is that immigration only minimally affects both, but it does have an impact on the number of live births. We use multiple indicators for each concept in order to better understand how each has changed over time.

\section{a. Fertility ${ }^{1}$}

In 1975 , Spain's fertility rate was a respectable 2.803 , but by the early 1980 s it dipped below replacement, and reached a low point of 1.161 in 1996 (Instituto Nacional de Istadistica: www.ine.es). Since then the Spanish fertility rate has remained below replacement. Our discussion in this section focuses on four measures of fertility in Spain - the total fertility rate, the crude birth rate, the average age of maternity among Spanish women, and the average age of Spanish women at first birth for the years 1975 to 2007. These data may be found in Table $\mathbf{1}$.

\section{Table 1. Fertilty Measures: Spain}

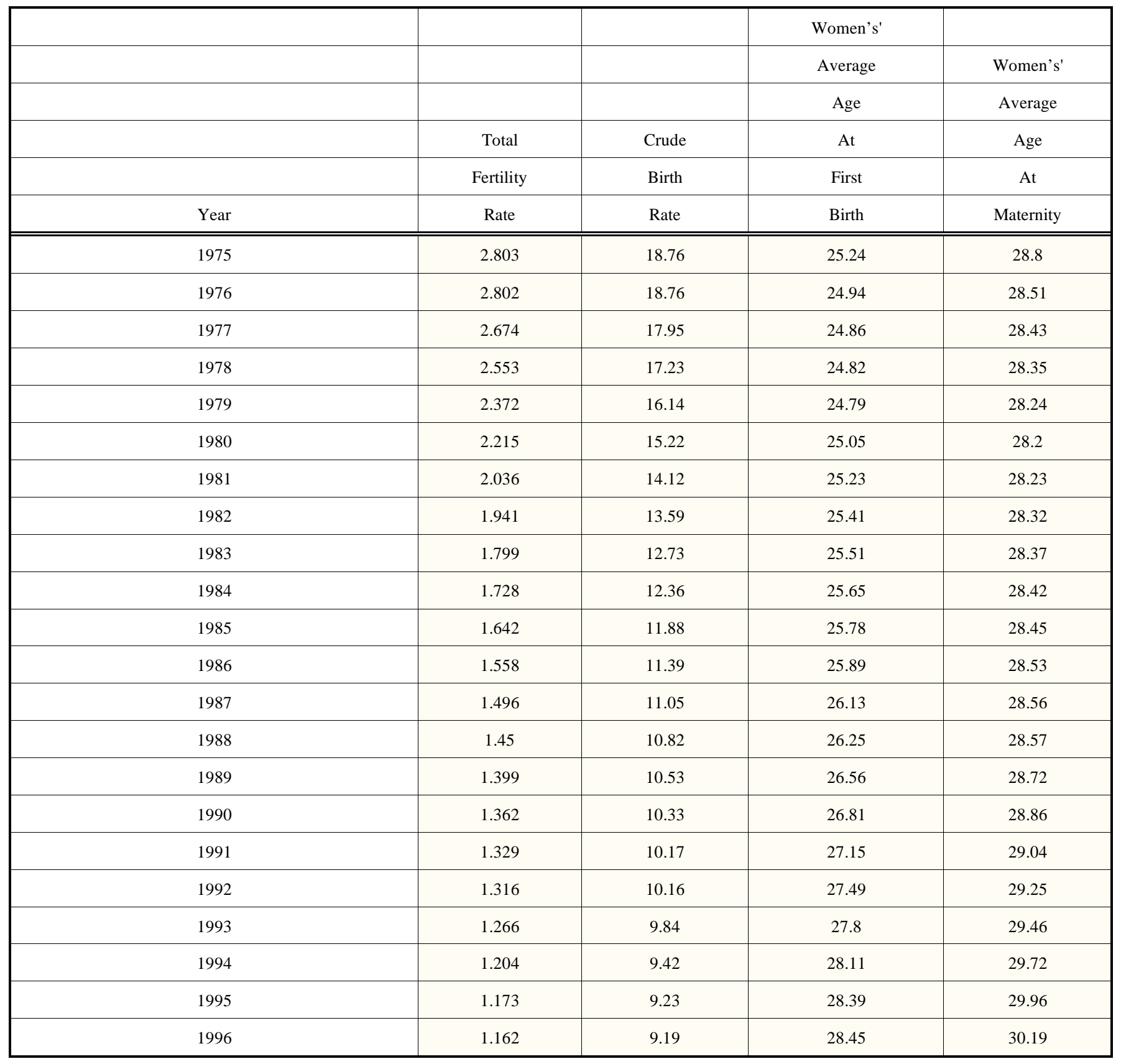


Table 1. contd...

\begin{tabular}{|c|c|c|c|c|}
\hline & & & Women's' & \\
\hline 1997 & 1.175 & 9.32 & 28.68 & 30.37 \\
\hline 1998 & 1.155 & 9.19 & 28.87 & 30.54 \\
\hline 1999 & 1.194 & 9.52 & 28.97 & 30.66 \\
\hline 2000 & 1.234 & 9.88 & 29.08 & 30.72 \\
\hline 2001 & 1.244 & 9.98 & 29.1 & 30.75 \\
\hline 2002 & 1.263 & 10.14 & 29.18 & 30.79 \\
\hline 2003 & 1.31 & 10.52 & 29.24 & 30.84 \\
\hline 2004 & 1.329 & 10.65 & 29.29 & 30.86 \\
\hline 2005 & 1.346 & 10.75 & 29.33 & 30.9 \\
\hline 2006 & 1.382 & 10.96 & 29.31 & 30.89 \\
\hline 2007 & 1.387 & 10.95 & NA & NA \\
\hline \% Chge 1975 - 2007/06 & -50.52 & -41.63 & 16.13 & 7.26 \\
\hline
\end{tabular}

Source: Instituto Nacional de Estadistica. www.ine.es NA= Not available

The Total Fertility Rate (TFR) in Spain has increased since about 2000, but has been stuck at below replacement, 1.38 children per females of child bearing age, since about 1981.

The crude birth rate (CBR) is another measure of fertility. The CBR measures the total number of births per 1000 persons in a population. Data displayed in Table 1 indicate that the Spanish CBR has been decreasing since 1975. In 1975 , there were 18.76 births per 1000 Spanish population, and by 2007 the CBR dropped to nearly 11 births per 1000 population (10.95). What is also interesting with these data is the slight upturn since about 1999--In 1999, the CBR was 9.52 and by 2007 it had moved to 10.95 .

Previous research has noted that part of the declining fertility rate in Spain is due to Spanish women putting off having children to later ages $[13,15,16]$. There have been a number of explanations for this phenomenon, including the greater educational and labor market opportunities available to Spanish women. With these greater economic opportunities Spanish women are delaying child birth. From 1975 to 2006, the average age of maternity among Spanish women increased. In 1975, the average age of maternity was 28.8 and by 2006 it climbed to 30.89 , or an increase of 7.26 percent.

As a final measure of fertility in Spain we looked at the average age at first birth among Spanish women. These data are different from those of average age of maternity and indicate, as expected, that Spanish women at first birth tend to be younger than the average age of maternity, though there is an upward trend for first-time mothers. In 1975, the average age at which a Spanish woman had her first child was 25 years of age. Average age at first birth reached a low of less than 25 years in 1979, but began to rise again, so that by 2006 it reached an average age of slightly greater than 29 years (29.31), or a 16.13 percent increase between 1975 and 2006.

\section{$\underline{\text { b. Mortality }}$}

Mortality also contributes to demographic change. Mortality in Spain, as suggested by previous research, has declined. The decline in mortality can be seen in such trends as an ageing population. For example, an ageing population raises the dependency ratio, a measure of the financial responsibility younger cohorts have for older cohorts. We examined three mortality measures in Spain: the proportion of the population age 65 or older; life expectancy at birth by gender; and the old age dependency ratio. These are displayed in Table 2.

The proportion of the Spanish population age 65 and older increased only slightly between 1997 and 2008: in 1997 the percent of Spaniards age 65 and older was 15.8, and by 2008 the percent had increased to 16.6 percent or a 5.1 percent increase over that eleven year time span. What is somewhat remarkable about these age data is their consistency; they have not varied much over time.

The old age dependency ratio (ODR) is the ratio between the total number of elderly persons (age 65+) and the number of working age persons (age 19-64). The ODR measures the responsibility a younger cohort has for taking care of an older cohort. In Spain the ODR grew by about one percentage point between 1997 and 2008-from 23.2 percent to 24.1 percent (a 3.88 percent change). In short, there were 23.2 elderly persons dependent on 100 workers in 1997, and by 2008 the number grew to 24.1 elderly dependents. So, though the responsibility for younger cohorts has increased it did not do so significantly.

As a final measure of the mortality concept, we examined life expectancy at birth (LEB) by gender. These data highlight the well-known pattern that females outlive men. Among males, the LEB in 1995 was 74.4 years and by 2006 it had risen by over three years to 77.7 years. Among females the increase was about the same, but females start out 
Table 2. Mortality Data: Spain

\begin{tabular}{|c|c|c|c|c|}
\hline & & Life & Life & \\
\hline & Age & at Birth & at Birth & Dependency \\
\hline Year & $65+$ & Male & Female & Ratio \\
\hline 1995 & & 74.40 & 81.80 & \\
\hline 1997 & 15.8 & 75.20 & 82.30 & 23.2 \\
\hline 1998 & 16.2 & 75.30 & 82.40 & 23.7 \\
\hline 1999 & 16.5 & 75.30 & 82.40 & 24.1 \\
\hline 2000 & 16.8 & 75.80 & 82.90 & 24.5 \\
\hline 2003 & 16.9 & 76.30 & 83.00 & 24.7 \\
\hline 2004 & 16.9 & 76.90 & 83.70 & 24.6 \\
\hline 2005 & 16.8 & 77.00 & 83.70 & 24.4 \\
\hline 2006 & 16.7 & 77.70 & 84.40 & 24.3 \\
\hline 2007 & 16.6 & NA & NA & 24.2 \\
\hline 2008 & 16.6 & NA & NA & 24.1 \\
\hline$\%$ change 1995 to 2006 & & 4.44 & 3.18 & \\
\hline
\end{tabular}

Source: Instituto Nacional de Estadistica:

www.ine.es $\mathrm{NA}=$ Not available

with a greater LEB measure. In 1995, the female LEB was nearly 82 (81.8) and by 2006 it had risen to 84.4 years. So, Spanish women have maintained their approximate 7-year advantage. None the less, note that all Spaniards are living into older ages.

\section{c. Immigration}

Immigration has remained an important yet controversial topic. One important, and controversial, topic has been whether immigrants can be a remedy for declining populations in Europe [see 4]. The general impression that one gets from this body of research is that immigration can slow down population decline but it won't stop it. In studies that estimate the immigrant population and how many are needed to stabilize a society, the extent literature is inconclusive. For Spain, however, research suggests that immigration has been an important factor in its growing economy [1, 17-19]. Consequently, because Spain has flourished it has welcomed immigrants for the past decade or so, though in recent years as the Spanish economy has floundered, as have economies throughout Europe, Spain is no longer as welcoming towards immigrants.

The number of immigrants in Spain increased significantly between 1998 to 2008. In 1998, there were an estimated 637,085 immigrants in Spain, and by 2008 the esti- mated number had increased to $5,268,762$. In short, between 1998 and 2008 the immigrant population in Spain grew by 727.01 percent. Fig. (3) shows the growth in Spain's immigrant population from 1998 to 2008. (Also see Table 3.) It appears that the greatest increases in Spain's immigrant population began in 2000; it then flattened out to some extent for the next four years. Immigrant growth started up again in 2004 and continued into 2008. In fact, from 2000 to 2008 , the average increase in the immigrant population was approximately 500,000 per year.

\section{B. Immigration and Its Impact on Demographic Change in Spain}

\section{Immigration and Population Change}

We estimate the impact immigration has on demographic change in Spain by looking at the percent of the Spanish population that are immigrants, by examining their share of population growth, and by looking at population growth net of immigration.

In 1998, the total population in Spain was $39,852,651$, and of this number, 637,085 were immigrants; that is, in 19981.6 percent of the population in Spain was immigrants. By 2008, the proportion of the total Spanish population that was immigrants increased to 11.5 percent. (See data in Table 


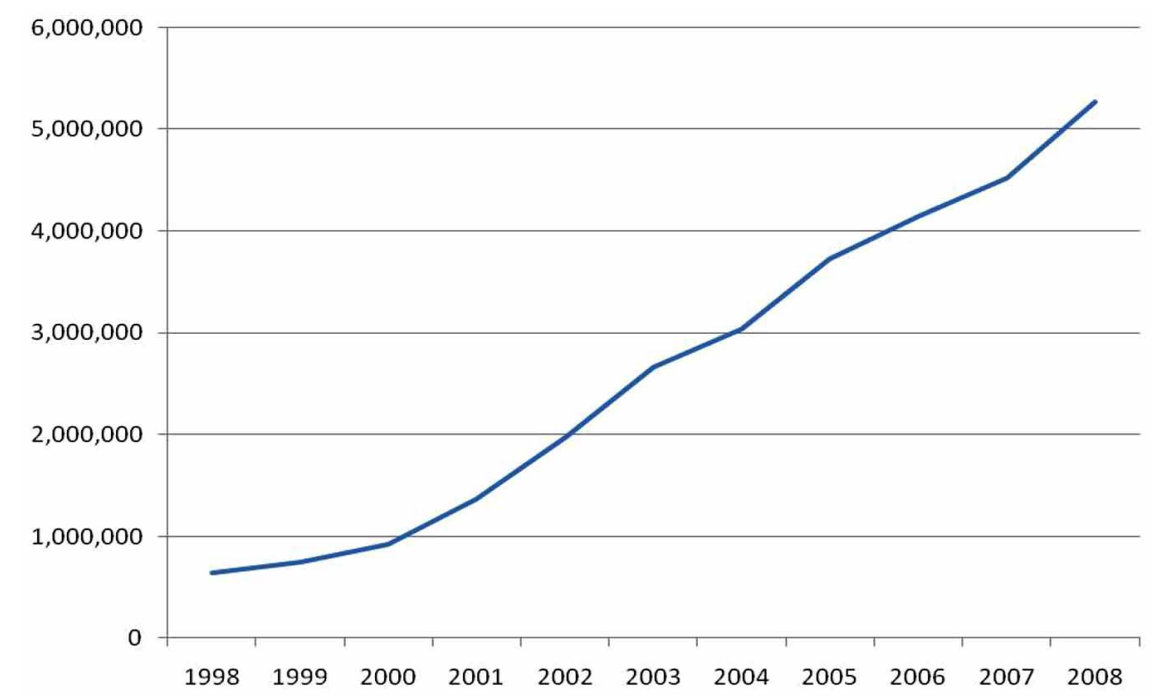

Fig. (3). Immigrant Population in Spain: 1998-2008.

Table 3. Impact of Immigration in Spain: Population

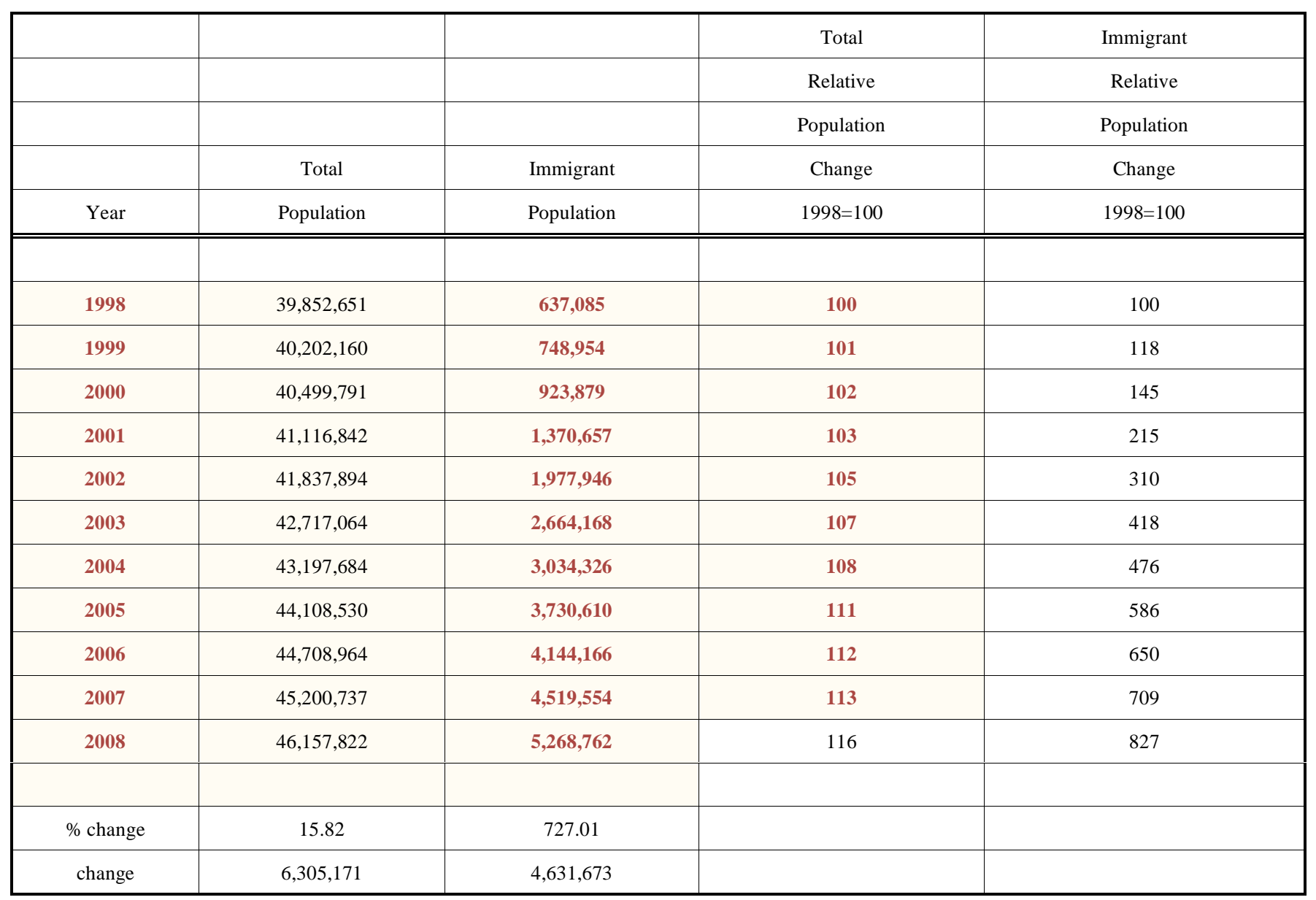

Source: Instituto Nacional de Estadistica. www.ine.es

3.) Clearly, the immigrant population in Spain has a significant impact on population change.

We also examined the relative change in the total population in Spain and compared it to the relative change in the immigration population as a second way of assessing the effects immigration has on population change in Spain. The base year is 1998 (See Table 3 \& Fig. 4). As can be seen, the relative increase in the immigrant population is significantly greater than the national population. The critical transition year appears to be 2000, when immigrant growth changed 
Table 4. Immigrant Fertility and its Impact on Fertility in Spain

\begin{tabular}{|c|c|c|c|c|}
\hline & & & Non & Immigrant \\
\hline & Non & & Immigrant & Crude \\
\hline & immigrant & immigrant & Birth & Birth \\
\hline Year & Live & Live & Rate & 24.12 \\
\hline \hline 1998 & Births & Births & 8.69 & 24.71 \\
\hline 1999 & 338,825 & 15,368 & 9.26 & 26.67 \\
\hline 2000 & 361,627 & 18,503 & 9.53 & 24.42 \\
\hline 2001 & 372,988 & 24,644 & 9.54 & 22.35 \\
\hline 2002 & 372,905 & 33,475 & 9.61 & 20.28 \\
\hline 2003 & 374,648 & 44,198 & 9.95 & 22.59 \\
\hline 2004 & 387,853 & 54,028 & 9.90 & 20.84 \\
\hline 2005 & 391,958 & 62,633 & 9.99 & 19.69 \\
\hline 2006 & 396,112 & 70,259 & 10.05 & 20.29 \\
\hline 2007 & 399,643 & 78,814 & 93,486 & \\
\hline
\end{tabular}

Source: Instituto Nacional de Estadistica.

www.ine.es

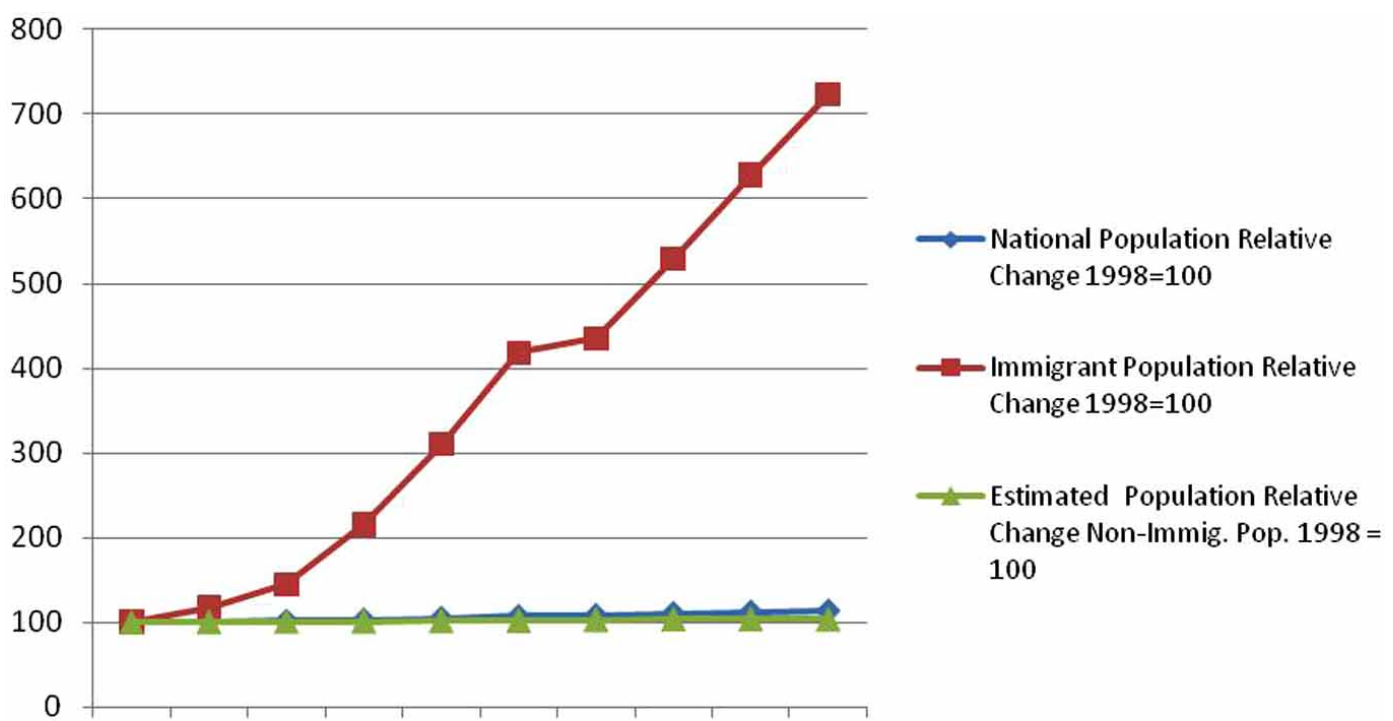

1998199920002001200220032004200520062007

Fig. (4). Relative Population Changes Among National, Immigrant, and Estimated Non-Immigrant Polulations: 1998-2007(1998=100).

from 145 in 1999 to 215 in 2001. Since about 2000 the growth of the immigrant population in Spain has been dramatic.

As a final measure of the impact immigration has on the population in Spain, we asked. a simple question, "If there were no immigrants in Spain, would the Spanish population have increased?" Between 1998 and 2008, the total population in Spain increased by 15.82 percent, the immigrant population by 727.01 percent, and if there were no immigrants at all in Spain (that is, if we just focused on the growth of the non-immigrant population); the population in Spain would have grown by only 4.27 percent. Another of saying the same thing, but highlighting the impact of immi- gration on population growth in Spain, would be to say that about 74 percent of the population growth in Spain was due to the growth in its immigrant population.

\section{Immigration and Fertility-Related Issues}

There are two important facts that research bears out regarding fertility. First, it is a well known that fertility rates of less than 2.1 are not going to replace a population. A second important demographic fact is that immigrants tend to have higher fertility rates than non-immigrants. We compared several fertility measures among immigrants and nonimmigrants in Spain. We should point out, though, that are analyses are limited to the Crude Birth Rate and to the total number of live births. (See table 4.). 


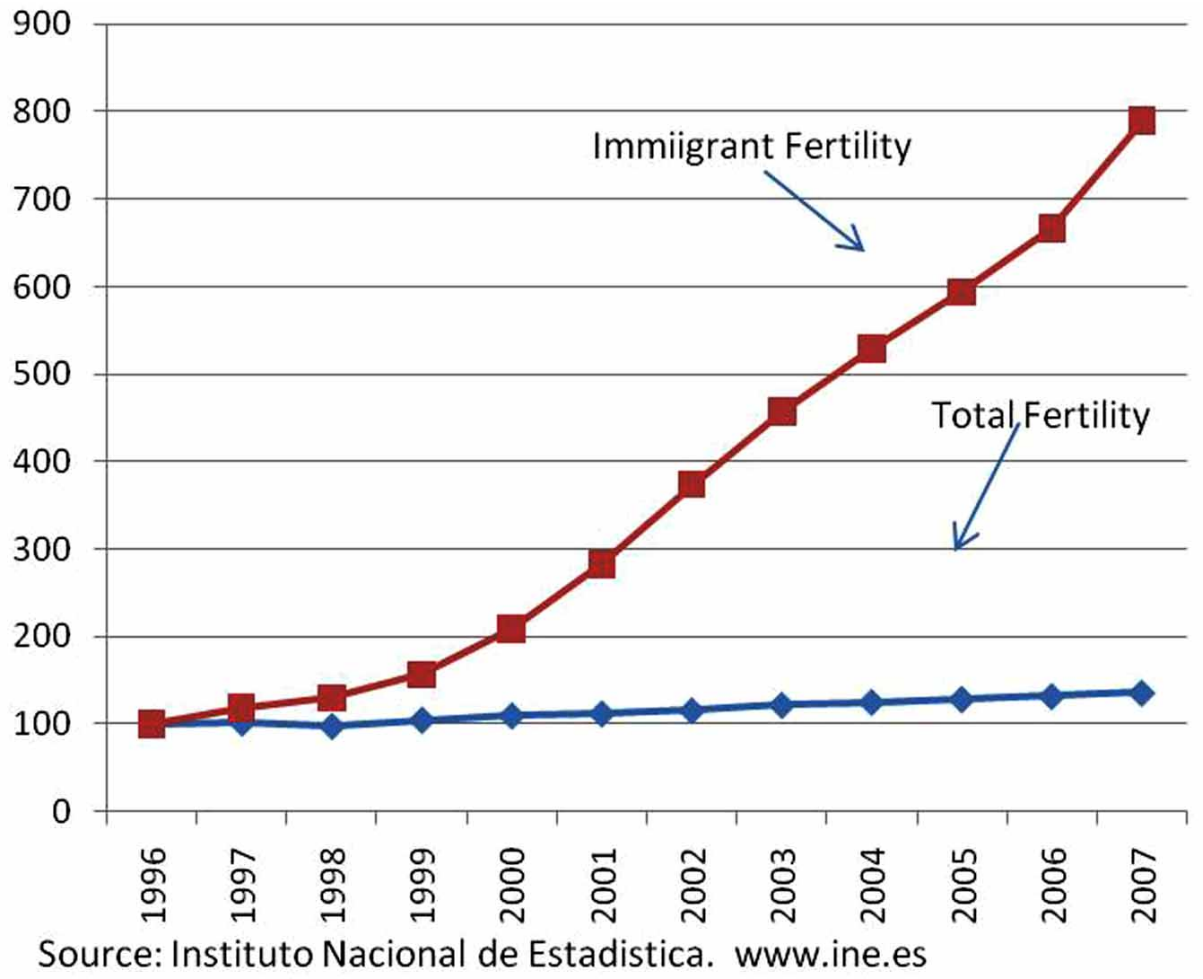

Fig. (5). Total and Immigrant births in Spain, 1996 to 2007 (1996=100).

Is the fertility among immigrants greater than nonimmigrants in Spain? Table 4 contains data on the Crude Birth Rate (CBR) for both groups for the years 1998 to 2007. There are three important stories in this table. First, it is clear that the CBR among immigrants has declined significantly since 1998. Indeed, between 1998 and 2007, the immigrant CBR declined by four (4) births per 1000 persons. A second story is that the CBR among immigrants is significantly greater than the CBR among non-immigrants. In fact, the immigrant CBR has varied from 2 to 2.5 times greater than the non-immigrant CBR over the time frame, 1998-2007. None the less, since about 2005, the gap in the CBRs has narrowed. Finally, we see that the non-immigrant CBR has grown, if ever so slightly, since 1998. In 1998, the nonimmigrant CBR was 8.69 births per 1000 non-immigrants in Spain, and by 2007 it had grown to 10.0 births per 1000 nonimmigrants.

Another way of comparing the fertility of immigrants and the non-immigrant Spanish population is to compare the Relative Growth in Live Births (RGLB) of both groups. These data are displayed in Fig. (5).

The growth of the RGLB among immigrants has been phenomenal. Between 1996 and 2007, the RGLB grew by nearly 700 percent (690.1 percent). The crucial take-off point appears to have been in 2001: the RGLB grew by 75 percent from its 1996 origin. In contrast to the immigrant RGLB, the total RGLB has remained flat since 1996. In fact, since 1996 the total RGLB among the total Spanish population varied from 400,000 to 500,000 . As a result of the steep increase in the immigrant RGLB, the impact of immigrant fertility on national live births also increased. In 1996, the immigrant live births as a percent of national live births was 3.2 percent and it jumped to 18.98 percent in 2007.

\section{Immigration and Mortality-Related Issues}

Between 1998 and 2007, the total number of deaths in Spain increased. In 1998, there were approximately 360,100 deaths in Spain. By 2007, the number of deaths increased to about 385,400 , or an increase of 7.03 percent. In contrast, the number of deaths among immigrants increased even more. In 1998, there were 6,530 immigrant deaths in Spain and by 2007 the figure grew to 10,600 , or an increase of 62.3 percent. (See Table 5.)

Immigrant mortality is not a significant part of total mortality. We computed immigrant mortality as a percent of total population mortality in Spain from 1998 to 2007. In 1998, immigrant deaths were about 2 percent of total deaths in Spain; by 2007, the percent increased to 2.75 percent.

As a final measure of the impact immigrant mortality has on total mortality in Spain, we "removed" immigrant deaths from the total number of deaths and asked how this would affect the mortality trend in Spain from 1998 to 2007. We then compared four Relative Growth Mortality trends: total mortality, immigrant mortality, non-immigrant mortality, and immigrant mortality as a percent of total mortality. (See Fig. 6).

Mortality, in terms of its growth from 1998 to 2007, varies greatly by immigrant status. If we look at the mortality growth of the total Spanish population, the trend has been exceedingly flat. For example, in 1998, the number of deaths in Spain was 360,100, and by 2007 it increased only slightly to 385,400 . Non-immigrant mortality has also remained fairly flat over time. In contrast, note the two other growth curves. Immigrant mortality and immigrant mortality as a percent of total mortality have steeper growth trends. While both are nearly equal in terms of their growth, it appears that immigrant mortality is slightly steeper, and in recent years 
Table 5. Total Deaths and Immigrant Deaths, 1998 to 2007 (Thousands)

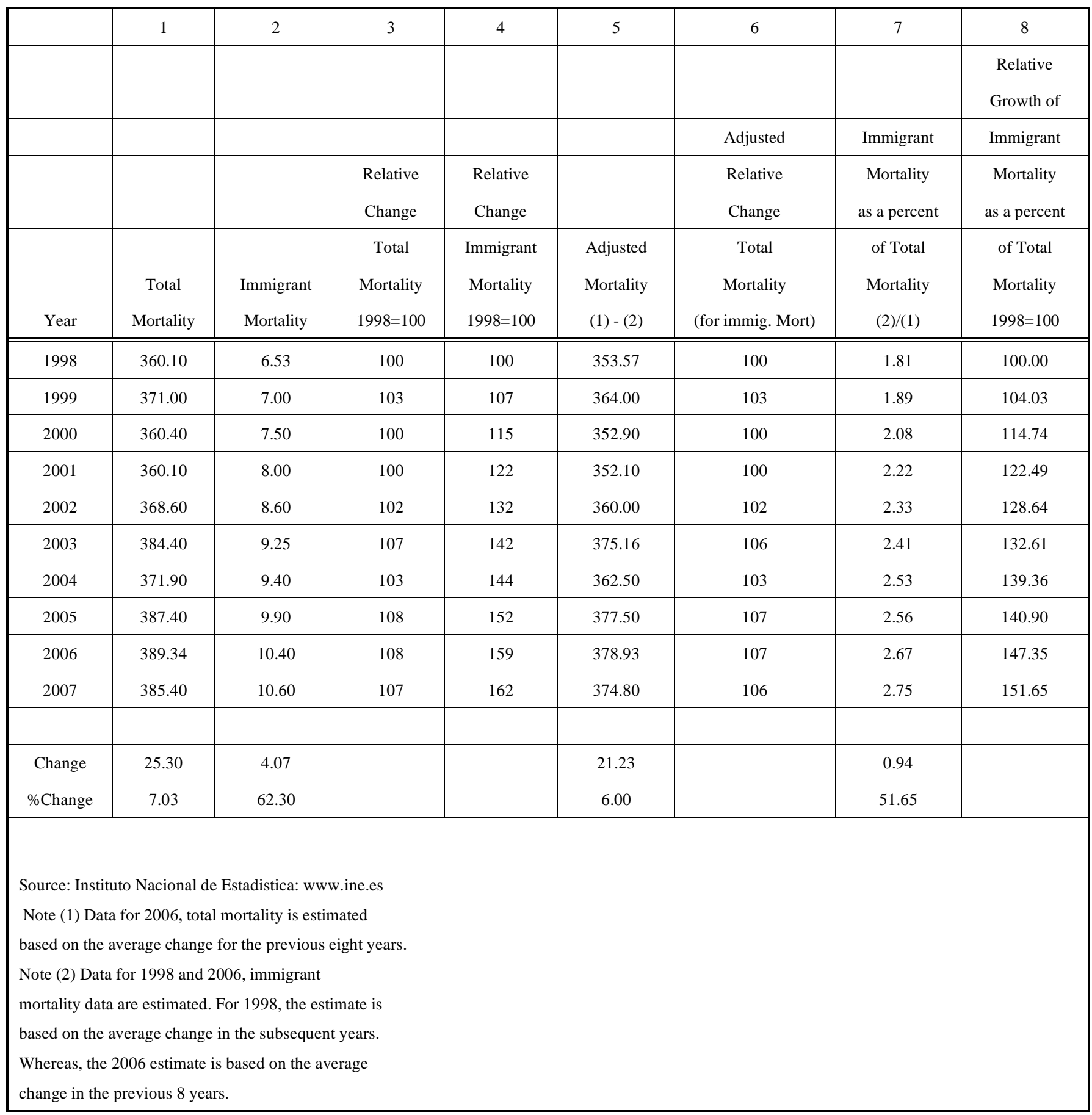

has picked up its upward trend. So, is immigrant mortality having an impact on the mortality in Spain? Our analyses thus far suggest that while immigrant mortality has increased significantly since about 1998, it is not having a major impact on total mortality in Spain.

\section{The Effects of Immigration on Demographic Change: The Balancing Equation}

The single most important question driving our analysis is, "Does immigration take a dominant role in the demographic changes occurring in Spain?" In attempting to pro- vide an answer to this question we employ a simple difference equation:

$$
\mathrm{P}_{\mathrm{t}+1}-\mathrm{P}_{\mathrm{t}}=\left(\mathrm{NI}_{\mathrm{t}+1}-\mathrm{NI}_{\mathrm{t}}\right)+\left(\mathrm{I}_{\mathrm{t}+1}-\mathrm{I}_{\mathrm{t}}\right)
$$

Where $P_{t+1}=$ Population at the end of the period, $P_{t}=$ population at the beginning of the period, $\mathrm{NI}_{\mathrm{t}+1}=$ the nonimmigrant population at the end of a period, $\mathrm{NI}_{t}=$ the nonimmigrant population at the beginning of a period, $\mathrm{I}_{\mathrm{t}+1}=$ the immigrant population at the end of a period, and $\mathrm{I}_{\mathrm{t}}=$ the immigrant population at the beginning of a period. We use the equation to assess the impact of immigration on demo- 


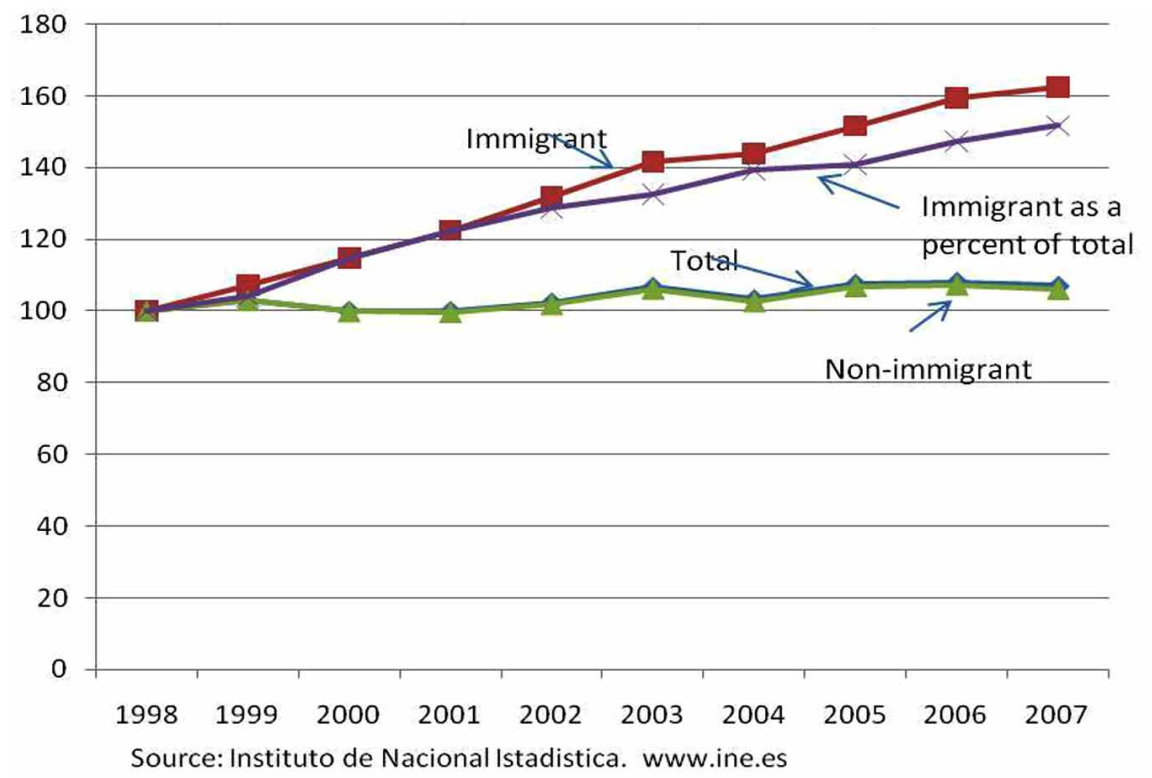

Fig. (6). Mortality Growhth Rates $(1998=100)$ from 1998 to 2007.

Table 6. The Contribution of Immigration to Population Change in Spain: 1998 - 2008

\begin{tabular}{|c|c|c|c|c|c|c|c|}
\hline & (1) & (2) & (3) & (4) & (5) & (6) & (7) \\
\hline & & & & & & Non & Im share \\
\hline & & & Non & Total & Immigrant & Immigrant & of total \\
\hline & Total & Immigrant & Immigrant & Population & Population & Population & population \\
\hline Year & Population & Population & Population & Change & Change & Change & Change \\
\hline 1998 & $39,852,651$ & 637,085 & $39,215,566$ & & & & \\
\hline 1999 & $40,202,160$ & 748,953 & $39,453,204$ & 349,509 & 111,868 & 237,638 & 32.01 \\
\hline 2000 & $40,499,791$ & 923,879 & $39,575,911$ & 297,631 & 174,926 & 122,707 & 58.77 \\
\hline 2001 & $41,116,842$ & $1,370,657$ & $39,746,185$ & 617,051 & 446,778 & 170,274 & 72.41 \\
\hline 2002 & $41,837,894$ & $1,977,946$ & $39,859,948$ & 721,052 & 607,289 & 113,763 & 84.22 \\
\hline 2003 & $42,717,064$ & $2,664,168$ & $40,052,896$ & 879,170 & 686,222 & 192,948 & 78.05 \\
\hline 2004 & $43,197,684$ & $3,034,326$ & $40,163,358$ & 480,620 & 370,158 & 110,462 & 77.02 \\
\hline 2005 & $44,108,530$ & $3,730,610$ & $40,377,920$ & 910,846 & 696,284 & 214,562 & 76.44 \\
\hline 2006 & $44,708,964$ & $4,144,166$ & $40,564,798$ & 600,434 & 413,556 & 186,878 & 68.88 \\
\hline 2007 & $45,200,737$ & $4,519,554$ & $40,681,183$ & 491,773 & 375,388 & 116,385 & 76.33 \\
\hline 2008 & $46,157,822$ & $5,268,762$ & $40,889,060$ & 957,085 & 749,208 & 207,877 & 78.28 \\
\hline 1998 & & & & & & & \\
\hline to & & & & & & & \\
\hline 2008 & $6,305,171$ & $4,631,677$ & $1,673,494$ & & & & 73.46 \\
\hline \multicolumn{2}{|c|}{$\%$ Change } & & & & & & \\
\hline 1998-08 & 15.82 & 727.01 & 4.27 & & & & \\
\hline
\end{tabular}

Source: Instituto Nacional de Estadistica. Www.ine.es Source: Instituto Nacional de Estadistica. Www.ine.es

graphic change in Spain. Data in Table 6 provides the results from the equation for the years 1998 to 2008.

Between 1998 and 2008, the impact of immigration on demographic change in Spain has been substantial. The equation below displays the impact immigration has had during the time interval 1998 to 2008.

$$
\Delta \mathrm{P}_{98-08}=\Delta \mathrm{NI}_{98-08}+\Delta \mathrm{IM}_{98-08}
$$


Where $\Delta \mathrm{P}_{98-08}=$ Population change between 1998 and 2008, $\Delta$ NI ${ }_{98-08}=$ change in the non-immigrant population from 1998 to 2008 , and $\Delta \mathrm{IM}_{98-08}=$ change in the immigrant population between 1998 and 2008 .

Between 1998 and 2008, the total population in Spain grew by $6,305,171$. Of this growth, immigrants to Spain accounted for $4,631,677$, or nearly 74 percent of the growth over that ten year period.

An analysis of one year intervals allows us to look at the evolution of demographic change. In the annual interval, 1998-99, immigration accounts for nearly a third of total population change in Spain, 32.01percent. Thereafter, the impact of immigration on population change in Spain has been even more substantial. In the annual interval, 19992000 , immigrants account for nearly 60 percent of the population growth in Spain (58.77 percent), and the greatest impact immigrants have had on population growth occurs in the annual interval, 2001-2002, when immigrants accounted for slightly over 84 percent of the population growth in Spain, 84.22 percent.

\section{CONCLUSION}

The question we addressed in this paper was, "Does immigration have an impact on demographic change in Spain?" In attempting to find an answer to our question we began by looking at fertility, mortality, and immigration trends in Spain. In a second analysis, we compared and contrasted trends in fertility and mortality in Spain with similar trends among immigrants. Finally, we used a difference equation in assessing the actual impact immigrants have had on demographic change in Spain. There were three important results from our study.

- While fertility and mortality increased slightly, immigration in Spain increased dramatically from 1998 to 2008 .

- Immigration does not have a major role in fertility or mortality rates, but does have a significant impact on population growth and live births.

- Our use of a simple difference equation indicates that immigrants have had a substantial impact on demographic change in Spain.

Have immigrants had an impact on demographic change in Spain? Given our findings, the only conclusions that can be drawn is that they have. Whether such an impact will continue into the future remains to be seen because of the current anti-immigrant views currently being displayed in Spain.

\section{NOTES}

${ }^{1}$ It should be stated that the use of the total fertility rate (TFR) has been a topic of much debate. In 1956, Ryder proposed a "translation" model to adjust for the period measures of fertility - the "tempo" on timing of childbearing. Ryder had noted that the TFR varied by changes in the timing of childbearing and sought to make some adjustments [19-21]. Ryder's method is based on two concepts: completed fertility and the mean age at childbearing per cohort. Ryder's linking equation is:

$$
\mathrm{TFR}=\mathrm{CFR} *(1-\theta),
$$

Where $\theta$ is the mean age of a cohort.

If the mean age does not change from one cohort to the next, then, of course, the relationship is $T F R=C F R$. However, if there is a change (increase or decrease) in mean age from one cohort to the next by, say, $\theta$, then,

$$
\mathrm{TFR}=\mathrm{CFR} *(1-\theta) .
$$

A positive change in $(\theta)$ would decrease CFR by $\theta$. However, if there is a decrease in $\theta$, then it would increase CFR by $1+\theta$.

But Bongaarts and Feeney [22] registered a complaint based on two issues. First, that Ryder assumes that changes in period fertility are the result of changes in the "tempo" and quantum of cohort fertility. The criticism has not been supported by the research [see [23] for a critique]). Second, it is argued that changes in mean age at childbearing may not result from timing but may result from declines in all higher order births, with the timing of individual births staying the same.

Bongaarts and Feeney [22], among others, offered an adjustment, which is simple in its execution, but difficult in its ability to get appropriate data. If the mean age at childbearing of any birth order is " $i$ " changes by $\theta$ per annum, then the number of births of order "I" is, $B_{i, a d j}=\left(B_{i, o b s} / 1-\theta\right)$. Note that $\theta=\partial a / \partial t$. Where a $=$ change in mean age from one cohort to the next, and $\mathrm{t}=$ the change in the time period of interest.

\section{REFERENCES}

[1] Enriquez CG. The other immigrants: EU citizens from rich countries. 2008. Available from: www.realinstitutoelcano.org. Working paper \#37/2008.

[2] Niessen J, Yongmi S. Demographic changes and the consequences for Europe's future: Is immigration an option? Brussels, Belgium: Migration Policy Group. 2002. Available from: www.migpolgroup. com

[3] Herm A. Recent migration trends: Citizens of EU-27 member states become ever more mobile while EU remains attractive to non-EU citizens. EUROSTAT: 2008. Available from: http://www.ec.europa.eu/eurostat

[4] Lutz W, Scherbov S. Can immigration compensate for Europe's low fertility? Luxenburg, Austria: International Institute for Applied Systems Analysis 2003. Available from: www.iiasa.ac.at.

[5] Reher D. Requerna M. The national immigrant survey of Spain: A new data source for migration studies in Europe. Dem Res 2009; 20(12): 253-78.

[6] Mujica JD, Dominguez J, Guerra TR. The new demographic and social challenges in Spain: The aging process and immigration. $\mathrm{Pa}$ per presented at the $4^{\text {th }}$ International Conference on Population Geographies, The Chinese University of Hong Kong, July 10-13, 2007.

[7] OECD. Internal migration outlook. 2008. Available from: www.oecd.org

[8] Sobotka T. Overview Chapter 7: The rising importance of immigrants for childbearing in Europe. Dem Res 2008; 19(9): 225-48.

[9] Ediev D, Coleman D, Scherbov S. Migration as a factor of population reproduction. Vienna, Austria: Vienna Inst of Dem of Aust Acad of Sci 2008.

[10] Frejka T. Overview Chapter 5: Determinants of family formation and childbearing during the societal transition in Central and Eastern Europe. Dem Res 2008; 19(7): 139-70.

[11] Frejka T, Sobotka T. Overview Chapter 1: Fertility in Europe: diverse, delayed, and below replacement. Dem Res 2008; 19(3): $15-46$. 
[12] Garssen J, Nicolaas H. Fertility of Turkish and Moroccan women in the Netherlands: Adjustment to native level within one generation. Dem Res 2008; 19(33): 1249-80.

[13] Mendes MF, Rebelo des Santos J. Planning to have a child: A socially conditioned decision? -Evidence from the European Social Survey (Round 2) for Spain and Portugal. Paper presented at the European Population Association meetings, Barcelona, Spain, July 9-12, 2008.

[14] Minet-Gamundi P. Reconstructing the fertility pattern of the 1960s Spanish birth cohort by parity progression ratios: Crisis, what crisis? Paper presented at the European Population Association meetings, Barcelona, Spain, July 9-12, 2008.

[15] Cantero PA. Reproductive behavior of immigrant Latin American women in Spain. Soc Med 2008; 3(2): 64-70.

[16] Delgado M, Meil G, López FZ. Spain: Short on children and short on family policies. Dem Res 2008; 19(27): 1059-104.
[17] Alfieri C. Spain: Immigrants make the economy grow. Barcelona, Spain: Inter Press Service News Agency 2009.

[18] Climent F, Meneu R. Demography and economic growth in Spain: A time series analysis. 2003. Available from: www.F.Jose.Climent @uv.es

[19] Ryder NB. La mesure des variation de la fecondite au cours du temps. 1956; 11(1): 29-46.

[20] Ryder NB. The process of demographic translation. Demography 1964; 1(1): 74-82.

[21] Ryder NB. Components of temporal variations in American fertility. In RW Hiorns ed. Demographic Patterns in Developed Societies. London: Taylor and Francis 1980; pp. 15-54.

[22] Bongaarts J, Feeney G. On the quantum and tem/20 of facility. Popul Dev Req 1998; 24(2): 271-91.

[23] Keilman N. Demographic translation: From period to cohort perspective and back. Memorandum, Department of Economics, University of Oslo. 2000. Available from: www.sv.uio.no/sosoek/

(C) Verdugo and Swanson; Licensee Bentham Open.

This is an open access article licensed under the terms of the Creative Commons Attribution Non-Commercial License (http://creativecommons.org/licenses/by-nc/3.0/) which permits unrestricted, non-commercial use, distribution and reproduction in any medium, provided the work is properly cited. 